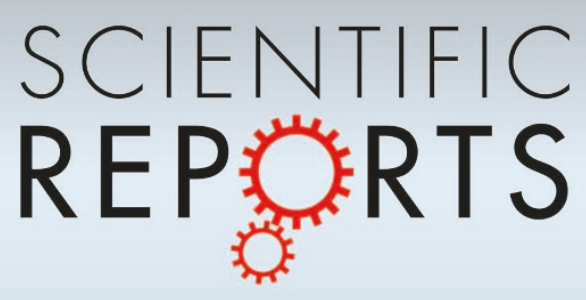

\title{
OPEN A molecular pathway for the egress of ammonia produced by nitrogenase
}

SUBJECT AREAS:

ENZYME MECHANISMS

METALLOPROTEINS

BIOCATALYSIS

DENSITY FUNCTIONAL THEORY

Received

16 July 2013

Accepted

1 November 2013

Published

18 November 2013

Correspondence and requests for materials should be addressed to

I.D. (i.dance@unsw. edu.au)

\author{
lan Dance
}

School of Chemistry, University of New South Wales, Sydney 2052, Australia.

Nitrogenase converts $\mathrm{N}_{2}$ to $\mathrm{NH}_{3}$, at one face of an Fe-Mo-S cluster (FeMo-co) buried in the protein. Through exploration of cavities in the structures of nitrogenase proteins, a pathway for the egress of ammonia from its generation site to the external medium is proposed. This pathway is conserved in the three species Azotobacter vinelandii, Klebsiella pneumoniae and Clostridium pasteurianum. A molecular mechanism for the translocation of $\mathrm{NH}_{3}$ by skipping through a sequence of hydrogen bonds involving eleven water molecules and surrounding aminoacids has been developed. The putative mechanism requires movement aside of some water molecules by up to $\sim 1 \AA$. Consistent with this, the surrounding protein is comprised of different chains and has little secondary structure: protein fluctuations are part of the mechanism. This $\mathrm{NH}_{3}$ pathway is well separated from the water chain and embedded proton wire that have been proposed for serial supply of protons to FeMo-co. Verification procedures are suggested.

T he enzyme nitrogenase converts dinitrogen to ammonia $\mathrm{N}_{2}$ to $\mathrm{NH}_{3}$, with some reduction of protons to dihydrogen: $\mathrm{N}_{2}+6 \mathrm{H}^{+}+6 \mathrm{e}^{-} \rightarrow 2 \mathrm{NH}_{3} ; 2 \mathrm{H}^{+}+2 \mathrm{e}^{-} \rightarrow \mathrm{H}_{2}$. There is considerable understanding of the biochemical processes of this enzyme. The two proteins that comprise nitrogenase are the MoFe protein in which the chemical catalysis occurs at the iron-molybdenum cofactor (FeMo-co), and the Fe protein where the reducing potential is generated. The catalytic site, FeMo-co, is an unprecedented $\mathrm{CFe}_{7} \mathrm{MoS}_{9}$ cluster (Fig. 1(a)) containing obligatory homocitrate (HCA, 2-hydroxybutane-1,2,4-tricarboxylate). Also in the MoFe protein is a redox-variable $\mathrm{Fe}_{8} \mathrm{~S}_{7}$ cluster called the P-cluster, approximately $12 \AA$ from FeMo-co, and understood to mediate electron transfer to FeMo-co. The Fe protein contains an $\mathrm{Fe}_{4} \mathrm{~S}_{4}$ cluster and the nucleotide (MgATP or MgADP) binding sites. The biochemical cycle involves docking of the Fe protein with the MoFe protein, hydrolysis of $2 \mathrm{MgATP}$, and transfer of one electron via the $\mathrm{Fe}_{4} \mathrm{~S}_{4}$ cluster at the docking interface to the P-cluster and then to FeMo-co ${ }^{1-9}$. This biochemical cycle of association, hydrolysis, electron transfer, dissociation is repeated eight times during reduction of $\mathrm{N}_{2}$ to $2 \mathrm{NH}_{3}$ with concomitant formation of $\mathrm{H}_{2}$.

The understanding of mechanism at the chemical level is poorer, in part due to experimental difficulties in trapping and characterising intermediates. However, investigations of the reactivities of proteins with modified residues have revealed the locus of chemical catalysis, the $\mathrm{Fe} 2, \mathrm{Fe} 3, \mathrm{Fe}$, $\mathrm{Fe} 7$, face of FeMo-co, and particularly the Fe2-S2B-Fe6 region directly underneath the side chain of $\alpha-70^{\text {Val }}{ }^{10-12}$. The surrounding residues $\alpha-195^{\text {His }}, \alpha-$ $191^{\mathrm{Gln}}, \alpha-69^{\mathrm{Gly}}$ and $\alpha-96^{\mathrm{Arg}}$ when modified also influence the reactivity of nitrogenase $\mathrm{e}^{6,8,13-22}$.

A series of density functional investigation ${ }^{23-27}$ has led to a detailed 21-step mechanism for the conversion of $\mathrm{N}_{2}$ to $\mathrm{NH}_{3}^{28,29}$. A key aspect of this mechanism is the serial formation, migration, and accumulation of multiple $\mathrm{H}$ atoms on FeMo-co, and their sequential transfer to bound substrates and intermediates to generate hydrogenated products ${ }^{25,30}$. Coupled electron transfer and proton transfer to FeMo-co are proposed to generate the $\mathrm{H}$ atoms at S3B. A requirement of this general intramolecular hydrogenation mechanism for nitrogenase is a controlled pathway for serial provision of external protons to S3B, and in a recent paper I described the chain of water molecules that leads from the surface of the protein to S3B, Fig. 1(b). A Grotthuss mechanism for serial translocation of protons along the fully conserved single chain of hydrogen bonded water molecules W8 to W1 (see Fig. 1(b)) to S3B was developed ${ }^{31}$. This inner section is a tight proton wire: the outer section is variable and is postulated to function as a proton bay.

In this paper I report explorations for the pathway used for diffusion of product $\mathrm{NH}_{3} / \mathrm{NH}_{4}{ }^{+}$from the reaction site to the surface of the protein. This product egress aspect of the activity of nitrogenase has been largely ignored. Durrant ${ }^{32}$ recognized the water chain that transports protons (Fig. 1(b)) and suggested that it could be used for transport of ammonia, but ammonia and protons cannot travel in opposite directions along the same water channel. The eight water molecules comprising the inner section of the proton wire are ideally hydrogen bonded to each other and to the enclosing homocitrate and key residues, in order to facilitate and control the Grotthuss proton transfer. Intrusion or substitution of $\mathrm{NH}_{3}$ here, and creation of $\mathrm{NH}_{4}{ }^{+}$, would block proton transfer to 
a

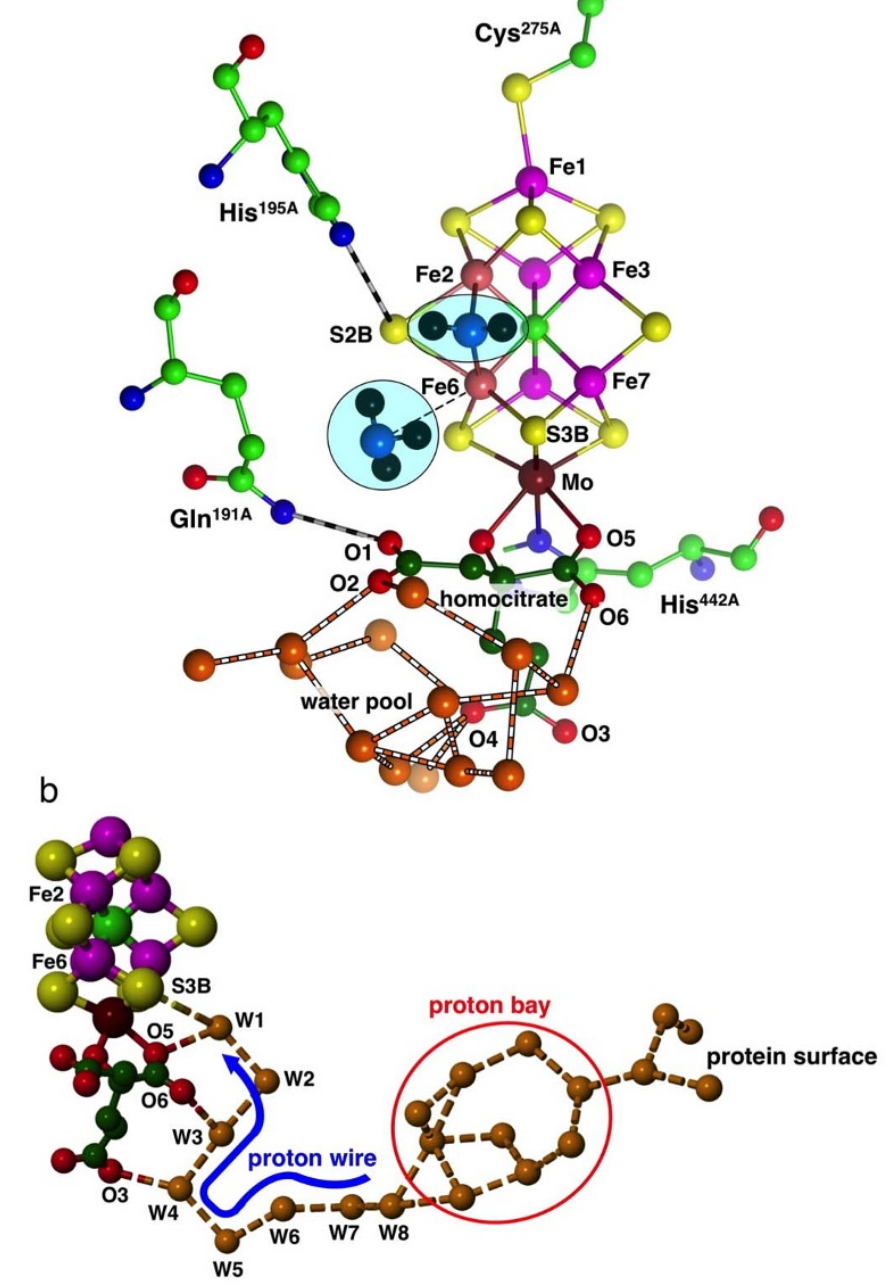

Figure $1 \mid$ (a) The structure of FeMo-co including homocitrate (carbon dark green) and ligating residues $\alpha-275^{\mathrm{Cys}}$ at Fe1 and $\alpha-442^{\text {His }}$ at Mo: atom labels are for the Azotobacter vinelandii protein in PDB 3U7Q. Also shown are key hydrogen bonded residues $\mathrm{Gln}^{191 \mathrm{~A}}$ and $\mathrm{His}^{195 \mathrm{~A}}$, and water molecules (orange) of the water pool around homocitrate, The first product $\mathrm{NH}_{3}$ molecule is dissociating from Fe6, the second is to be formed from $\mathrm{NH}_{2}$ bridging $\mathrm{Fe} 2$ and $\mathrm{Fe} 6$ (in this and some following figures $\mathrm{Fe} 2$ and $\mathrm{Fe} 6$ are coloured differently). (b) The chain of hydrogen bonded water molecules from the protein surface to S3B of FeMo-co. The proton wire section W8 to W1 is fully conserved, while the branched proton bay section and the path to the surface are variable.

FeMo-co (by the formation of too many hydrogen bonds to allow the Grotthuss proton hopping) and in the same manner would freeze translocation of ammonia. It is clear that separate pathways are needed for the proton supply to FeMo-co and the efflux of $\mathrm{NH}_{3}$. In the structures of MoFe proteins there is a collection of water molecules around homocitrate ${ }^{2}$, and it has been suggested that this water pool could absorb product ammonia ${ }^{31}$. However this does not account for transport of product ammonia to the protein surface, which is the question addressed here.

The translocation of ammonia through other proteins has been investigated in detail, principally for the ammonium transporter (Amt) proteins which control movement of $\mathrm{NH}_{3} / \mathrm{NH}_{4}{ }^{+}$across cell membranes in bacteria, archaea, fungi, plants and animals ${ }^{33-36}$, and for a collection of glutamine amidotransferase (GAT) enzymes. These latter enzymes utilise $\mathrm{NH}_{3}$, derived from the hydrolysis of glutamine, in a synthase reaction. They transport the $\mathrm{NH}_{3}$ from the generation site to a distant synthase domain through intramolecular tunnels protected from the environment ${ }^{37-42}$. The consensus interpretation, based on structural information, targeted mutations, molecular dynamics simulations, and calculation of intra-protein $\mathrm{pK}_{\mathrm{a}}$, is that $\mathrm{NH}_{3}$ rather than $\mathrm{NH}_{4}{ }^{+}$is the moving entity in these glutamine amidotransferases $\mathrm{s}^{37,43-47}$. However, the Amt proteins (and related human Rhesus proteins ${ }^{48,49}$ ) have different functions, including transport of $\mathrm{NH}_{4}{ }^{+}$against a concentration gradient and discrimination against $\mathrm{K}^{+}$. Three mechanisms are under consideration: transport of $\mathrm{NH}_{3}$, transport of $\mathrm{NH}_{4}{ }^{+}$, and co-transport of $\mathrm{NH}_{3}$ and $\mathrm{H}^{+} 33-35,50-59$.

\section{Results}

This investigation is based on detailed exploration of the structures of crystals containing the MoFe protein, from different species and in various trapped states, and including the independent occurrences of FeMo-co and surrounds in each protein. Unless stated otherwise, amino-acid numbering is that of the Azotobacter vinelandii $(A v)$ $\mathrm{MoFe}$ protein, and water molecules are labeled as in the highest resolution structure, $\mathrm{PDB} 3 \mathrm{U} \mathrm{Q}^{60}$. Residue labels contain letters $\mathrm{A}$, B. to denote the chain in the PDB file. In the following the term 'water path' is reserved for the collection shown in Fig. 1 (b), and the term 'water pool' refers to the different collection of water molecules around homocitrate (Fig. 1(a)).

Generation of $\mathrm{NH}_{3}$. Product $\mathrm{NH}_{3}$ molecules are expected to be generated close to the reaction face of FeMo-co. In the complete mechanism proposed for conversion of $\mathrm{N}_{2}$ to $\mathrm{NH}_{3}{ }^{28}$, the $\mathrm{NH}_{3}$ molecules are formed (late in the catalytic cycle) at atoms Fe6 and $\mathrm{Fe} 2$ of FeMo-co. The first $\mathrm{NH}_{3}$ is generated at the exo position of Fe6, from which it dissociates in the exo direction. The second $\mathrm{NH}_{3}$ is generated at the endo position of $\mathrm{Fe} 2$, and dissociates in an endo direction, looping around the endo side of Fe6. Residue $\mathrm{Val}^{70 \mathrm{~A}}$ and its neighbours in the $\alpha$-helix that covers the face of FeMo-co constrain both product $\mathrm{NH}_{3}$ molecules to leave in the exo direction from $\mathrm{Fe}$. This is illustrated in Fig. 1(a) that shows the first $\mathrm{NH}_{3}$ leaving Fe6, and the nascent second $\mathrm{NH}_{3}$ as an $\mathrm{NH}_{2}$ group bridging $\mathrm{Fe} 2$ and $\mathrm{Fe} 6$. The formation of the second $\mathrm{NH}_{3}$ is completed by $\mathrm{H}$ atom transfer from S3B, and after dissociation it is proposed to follow the path of the first $\mathrm{NH}_{3}$. Fig. 1(a) also locates the hydrogen bonded water molecules that comprise the water pool, clustering around the uncoordinated carboxylate atoms $\mathrm{O} 1, \mathrm{O} 2$ and $\mathrm{O} 4$ of homocitrate. The separate water chain that supports the proton wire to S3B of FeMo-co uses different homocitrate atoms O5, O6 and O3 (Fig. 1(b)). Residue Gln ${ }^{191 \mathrm{~A}}$, hydrogen bonded to $\mathrm{O} 1$ of homocitrate, lies approximately in the path of the departing $\mathrm{NH}_{3}$ molecules, whereas His $^{195 \mathrm{~A}}$ is out of the way.

Strategy. The search for possible channels and pathways was undertaken first by a search for cavities in the MoFe protein in the vicinity of FeMo-co and the water pool. The species generality of the cavities so located was checked, together with the generality of their occurrence in the best available crystal structures. The most promising cavities near the $\mathrm{NH}_{3}$ generation position were examined for size and extent, water content, and immediate surroundings. Then, in the one feasible cavity, possible locations for a moving $\mathrm{NH}_{3}$ molecule were modeled, with hydrogen bonding to water and protein surrounds. Finally, the most probable pathway was assessed in terms of protein tertiary structure and likely dynamic fluctuations during $\mathrm{NH}_{3}$ egress.

Calculations of pockets in the protein. The initial search for cavities involved calculations of pockets in the protein, using the program fpocket ${ }^{61}$. Pockets are clusters of intersecting alpha spheres. An alpha sphere contacts four atoms on its boundary and contains no internal atom: the four atoms are equally distant from the sphere centre, defining the radius of the sphere. The results reported used alpha 


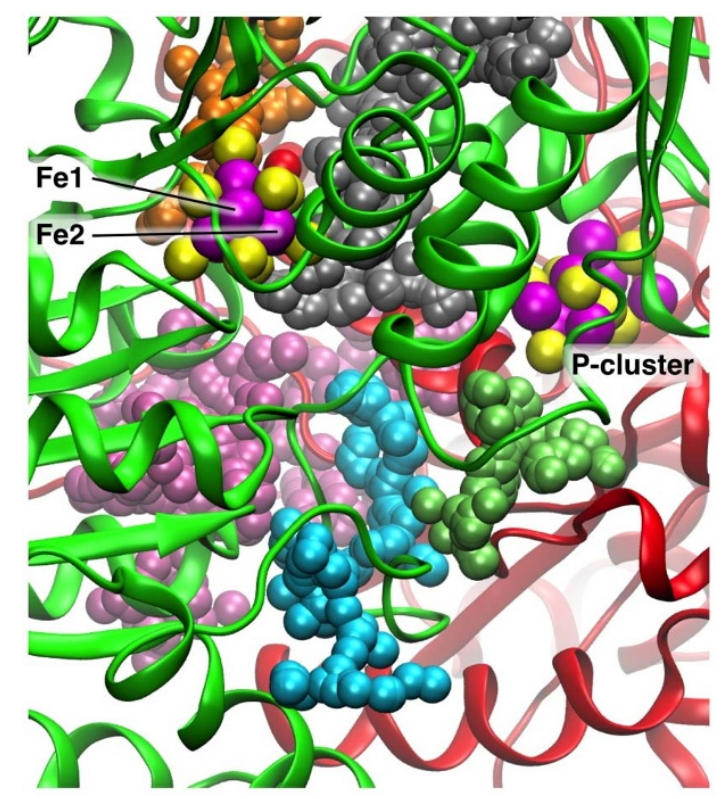

Figure $2 \mid$ Relevant pockets calculated for $A v$ protein, PDB 3U7Q. The pockets are represented as assemblies of alpha spheres, differentiated by colour. The view direction is directly along the pseudo-threefold axis of FeMo-co, from the top: Mo and homocitrate (HCA) are on the distant side of FeMo-co. The rotational orientation of FeMo-co is signified by the marked position of $\mathrm{Fe} 2$, and by the location of the P-cluster. The two protein chains that envelope the pockets are coloured green and red.

spheres with a minimum radius of $2.8 \AA$, and required at least 35 intersecting alpha spheres to constitute a pocket. Water molecules are ignored in the calculation of pockets, but were included in the results, in order to examine the presence of water in or near the pockets. Thus the pocket calculations yielded domains in the protein sufficiently large to contain $\mathrm{NH}_{3}$ or $\mathrm{NH}_{4}{ }^{+}$, and possibly containing water.

Calculations were made for all of the high-resolution crystal structures $\left(\mathrm{PDB} 3 \mathrm{U}^{\mathrm{Q}} \mathrm{Q}^{60}, 1 \mathrm{M}^{\mathrm{N}} \mathrm{N}^{62}, 2 \mathrm{MIN}^{63}, 3 \mathrm{MIN}^{63}, 2 \mathrm{AFH}^{64}, 2 \mathrm{AFI}^{64}\right.$, $\left.1 \mathrm{MIO}^{65}, 1 \mathrm{QGU}^{66}, 1 \mathrm{QH} 1^{66}, 1 \mathrm{QH} 8^{66}, 1 \mathrm{H}^{6} \mathrm{~L}^{67}\right)$ that include the MoFe protein and a high proportion of resolved water molecules, and encompassed the species Azotobacter vinelandii $(A v)$, Klebsiella pneumoniae (Kp) and Clostridium pasteurianum (Cp).

Figure 2 shows the significant pockets (drawn as aggregates of alpha spheres) found in the vicinity of FeMo-co for the $A v$ protein (PBD 3U7Q). The view direction in this figure is directly along the pseudo-threefold axis of FeMo-co, from the top. Two protein chains that envelop the pockets and cofactors are coloured green and red. In this and the following descriptions the pockets are labeled by their colours. The silver pocket contains the water molecules of the water pool, while the water path that supports the proton wire appears as the orange pocket extending upwards from FeMo-co. The key pocket is that coloured cyan, which extends from an edge of the silver pocket, twisting towards the surface of the protein. The inner section of the cyan pocket is very similar for the $A v$ and $K p$ proteins, but variation occurs as the pocket reaches the protein surface. The gap between the inside edge of the cyan pocket and the silver pocket is devoid of protein main chain, and the point of approach of the cyan and silver pockets is essentially unchanged for all of the protein crystals investigated. The lime pocket extends from the P-cluster, and has variable shape and size. In some protein structures it is larger than shown in Fig. 2, extending to the protein surface near where the cyan pocket meets the surface. The lime pocket is not near the water pool, and is separated from it by a section of polypeptide chain, and therefore the lime pocket is not believed to play any role in the movement of $\mathrm{NH}_{3}$, and it will not be considered further. The only

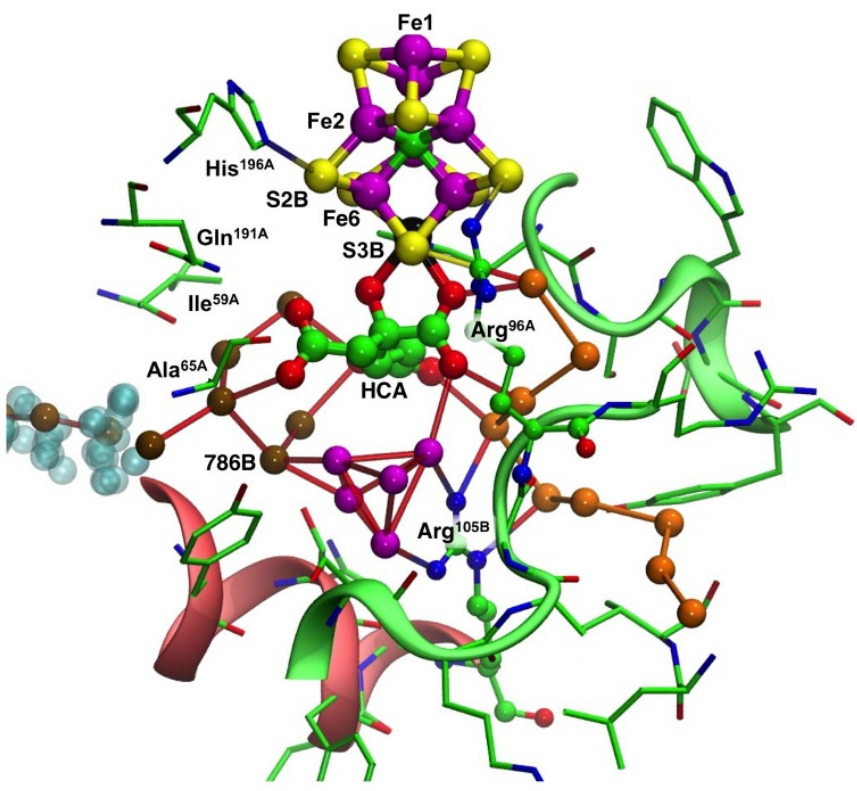

Figure 3 The water pool around homocitrate in the MoFe protein (Av, PDB 3U7Q). The hydrogen bonded water molecules of the proton wire are coloured orange. The water molecules extending from homocitrate towards the cyan pocket are coloured brown. Between these two sets of water molecules is a compact cluster of water molecules coloured magenta. Connecting lines from the water molecules signify contacts at hydrogen bond distances. Two significant amino acids, $\operatorname{Arg}^{105 \mathrm{~B}}$ and $\mathrm{Arg}^{96 \mathrm{~A}}$, are drawn with atom spheres. Cartoon representations of significant parts of chain A (green) and B (red) are included.

other pocket near the silver pocket is that coloured mauve: this pocket has variable size and shape in different proteins, and is separated from the silver pocket by a gap of $6.4 \AA$ that is blocked by the sidechain of Lys426 ( $A v$, Lys424 in Kp).

These pocket calculations focus attention on the cyan pocket as the most likely domain for $\mathrm{NH}_{3}$ efflux. Before proceeding with more detailed investigation of this silver-plus-cyan domain of the protein, two further checks were made. The first involved the location of the region where the Fe protein docks with the MoFe protein during the electron transfer cycle, in relation to the postulated exit point for $\mathrm{NH}_{3}$ on the surface of the MoFe protein. This was to determine whether diffusion of $\mathrm{NH}_{3}$ from the surface of the MoFe protein might be blocked when the Fe protein is docked. Crystal structures 2AFH and $2 \mathrm{AFI}(A v)$ contain the Fe protein docked with the MoFe protein, using two different but adjacent docking domains, dependent on the state of the nucleotide in the Fe protein ${ }^{64}$. In both structures, the surface terminus of the cyan pocket is not part of the docking domain, and does not encounter the polypeptide chains of the Fe protein (supplementary Fig. S1).

The second check involved the relationship between the water pool postulated for $\mathrm{NH}_{3}$ movement away from FeMo-co and the chain of water molecules that constitutes the proton wire. Figure 3 shows the relevant part of the protein, around and 'underneath' homocitrate. The conserved chain of hydrogen-bonded water molecules comprising the proton wire (terminating with a hydrogen bond to $\mathrm{S} 3 \mathrm{~B}$ ) is depicted with orange spheres, while water molecules extending from the other side of homocitrate towards the alpha spheres of the cyan pocket are coloured brown. There is an additional cluster of water molecules, coloured magenta, directly under homocitrate. The composition and structure of this water cluster varies in the different crystal structures, and the geometry is such that not all of the hydrogen bond distances within this cluster could be hydrogen bonds. This cluster is hydrogen bonded to one 'brown' water molecule (786B) and is not hydrogen bonded directly to the proton wire. 

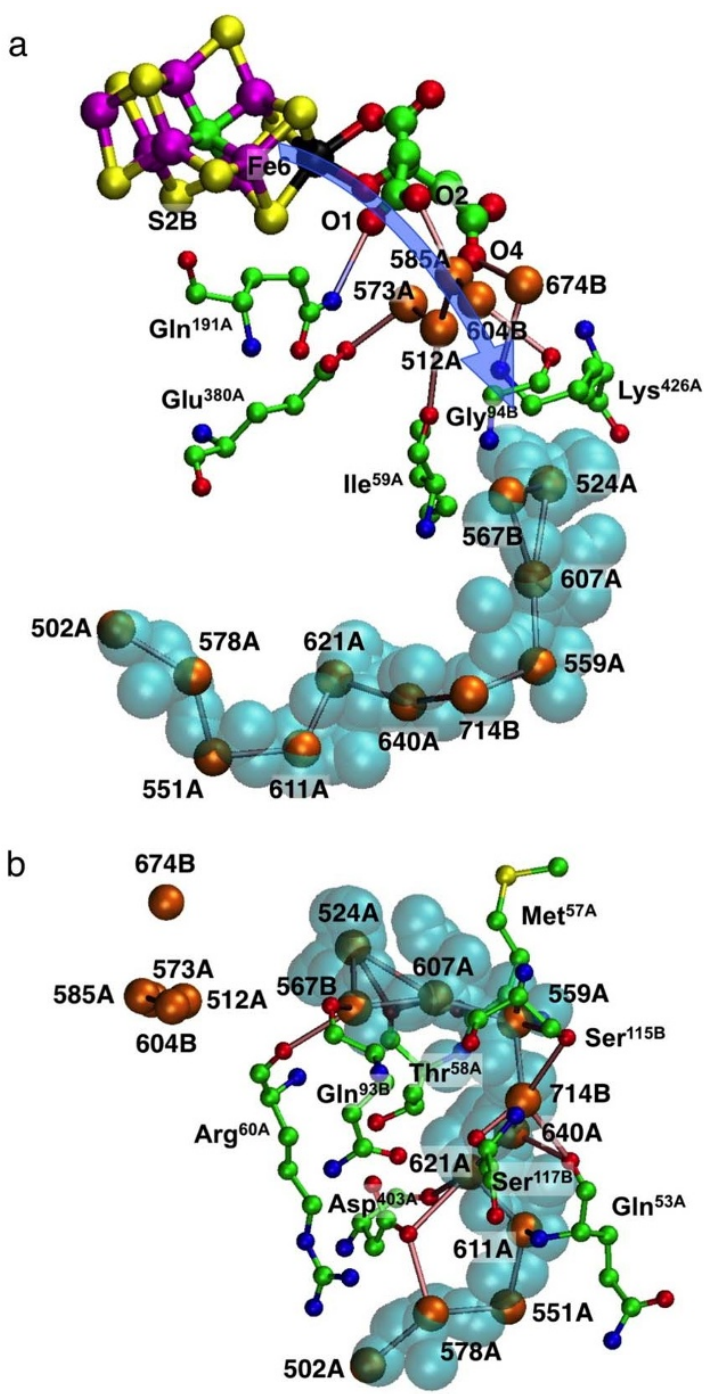

Figure $4 \mid$ The contents and immediate surroundings of the approach to the cyan pocket, and the cyan pocket, labeled for the $A v$ protein $(3 \mathrm{U} 7 \mathrm{Q})$. Atoms $\mathrm{O} 1, \mathrm{O} 2, \mathrm{O} 4$ of homocitrate are evident in (a), and the blue arrow depicts the general direction of $\mathrm{NH}_{3}$ movement from the reaction face of FeMo-co. Part (b) shows the relevant residues surrounding the cyan pocket and hydrogen bonding to the chain of water molecules. Hydrogen bonds between water molecules are marked.

The side-chain of arginine $\mathrm{e}^{105 \mathrm{~B}}$ is a barrier between the magenta cluster and the proton wire, and, as previously described, is a crucial part of the proton wire ${ }^{31}$.

It is clear from Fig. 3 that the putative ammonia path into the cyan pocket and the proton path occur in opposite directions through the protein, as required chemically. The water pool near homocitrate is comprised of the 'brown' and 'magenta' water molecules, not directly linked to the proton wire. The magenta water cluster does not appear to have a functional role other than as a small compact reservoir for water molecules.

Contents and surrounds of the postulated $\mathrm{NH}_{3}$ exit pathway. The next step was to examine closely the contents and immediate surroundings of the indicated ammonia pathway towards and through the cyan pocket. The blue arrow in Fig. 4(a) shows the proposed general direction of movement from the vicinity of $\mathrm{Fe} 6$ (cf Fig. 1(a)), over homocitrate and associated water molecules in the water pool, and towards the water molecules at the entrance of the cyan pocket. The relevant water molecules close to $\mathrm{O} 1, \mathrm{O} 2$ and
O4 of homocitrate are 573A, 512A, 585A, 604B and 674B, with hydrogen bond connections to amino acids, $\mathrm{Gln}^{191 \mathrm{~A}}$, $\mathrm{Glu}^{380 \mathrm{~A}}$, Lys $^{426 \mathrm{~A}}$, Ile ${ }^{59 \mathrm{~A}}$ and $\mathrm{Gly}^{94 \mathrm{~B}}$ (all labels here and following are those of the $A v$ protein, $\mathrm{PDB} 3 \mathrm{U} 7 \mathrm{Q})$. The gap between these water molecules and the entrance to the cyan pocket (the gap between silver and cyan pockets in Fig. 2) is surrounded by but not blocked by Lys ${ }^{426 \mathrm{~A}}, \mathrm{Ile}^{59 \mathrm{~A}}$ and Gly ${ }^{94 \mathrm{~B}}$.

The cyan pocket (of the $A v$ protein) contains a sequence of eleven hydrogen bonded water molecules, extending roughly in an arc. Around these there are interactions with $\mathrm{Met}^{57 \mathrm{~A}}, \mathrm{Thr}^{58 \mathrm{~A}}, \mathrm{Arg}^{60 \mathrm{~A}}$, $\mathrm{Gln}^{53 \mathrm{~A}}, \mathrm{Asp}^{403 \mathrm{~A}}, \mathrm{Ser}^{115 \mathrm{~B}}$ and Ser ${ }^{117 \mathrm{~B}}$, marked in Fig. 4(b).

It is postulated that $\mathrm{NH}_{3}$ egress starts from $\mathrm{Fe} 2 / \mathrm{Fe} 6$ on FeMo-co, following the direction of the blue arrow (Fig. 4(a)) and probably engaging with some of the hydrogen bonding components $\mathrm{O} 1, \mathrm{O} 2$, $\mathrm{O} 4$ of homocitrate, the five associated water molecules, and sidechains of $\mathrm{Gln}^{191 \mathrm{~A}}$, Glu ${ }^{380 \mathrm{~A}}$, $\mathrm{Lys}^{426 \mathrm{~A}}$. At this point the $\mathrm{NH}_{3}$ molecule would be positioned at the entrance of the cyan cavity, ready to move to the end of this cavity, engaging with the contained water and surrounding residues. If this hypothesis is correct, these features should be conserved in the various protein structures, and therefore details of these components and surroundings have been compared for the highest resolution crystal structures for $A v(3 \mathrm{U} 7 \mathrm{Q})$ and $K p$ (1QH1). Fig. 5, a comparison of the hydrogen bonding connectivities, demonstrates that the two proteins are very similar. The domains in this depiction, left to right, are first the water pool and its homocitrate components, then a gap to the sequence of water molecules and protein surrounds in the vicinity of the cyan cavity. Functions from the A and B chains are differentiated by colour.

The similarity of the two proteins is evident. The principal difference is the absence in $K p$ of a water molecule in the same position as water $640 \mathrm{~A}$ in $A v$, breaking the chain of hydrogen bonded water molecules, and changing some hydrogen bonding interactions with surrounding protein. This water is halfway through the cyan pocket

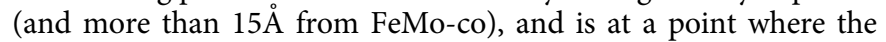
pathway possibilities for $\mathrm{NH}_{3}$ are diverging (see next section). In the $K p$ protein the hydroxyl side chain of Ser ${ }^{51 \mathrm{~A}}$ is near the position of water $640 \mathrm{~A}$ in $A v$, and is disordered, which is indicative of movements that could be part of $\mathrm{NH}_{3}$ passage here. These differences in the later section of the cyan pocket are consistent with the notion that as $\mathrm{NH}_{3}$ approaches the protein surface its mechanism for molecular translocation is less controlled.

Figure 5 also draws attention to the differentiation of main chain atoms (boxed) and side-chain groups in the hydrogen-bonding network, and the prevalent involvement of main chain carbonyl functions, as potential hydrogen bond acceptors. Residue Ile ${ }^{59 \mathrm{~A}}$ in $A v$ is $\mathrm{Val}^{58 \mathrm{~A}}$ in $K p$, but since it is the main chain carbonyl $\mathrm{O}$ that participates in the hydrogen bonding this difference of hydrophobic side chains is inconsequential. There are differences in the region of waters $674 \mathrm{~B}(3 \mathrm{U} 7 \mathrm{Q})$ and $25(1 \mathrm{QH} 1)$, and their hydrogen bonding with $\mathrm{Lys}^{426} / \mathrm{Lys}^{424}$, but this is not significant because these functions are distant from the detailed pathway described in the next section.

Atomic level mechanism for $\mathrm{NH}_{3}$ movement. The preceding analysis has revealed a possible pathway for movement of $\mathrm{NH}_{3}$ away from FeMo-co towards the protein surface. The questions now are (a) whether there is space for this movement of $\mathrm{NH}_{3}$, (b) whether the environment is consistent with the hydrogen bonding expected of $\mathrm{NH}_{3}$, (c) what impediments might exist, and (d) what fluctuations in the tertiary structure of the protein are likely to be involved. Possible pathways for molecular $\mathrm{NH}_{3}$ to move from FeMoco to and through the cyan cavity towards the surface of the protein were investigated by manual molecular modelling.

Since water and $\mathrm{NH}_{3}$ are similar in size and hydrogen bonding attributes, one question is whether $\mathrm{NH}_{3}$ might occupy the locations that are observed to contain water in the resting protein structures. [It is very unlikely that the crystallographically observed small 

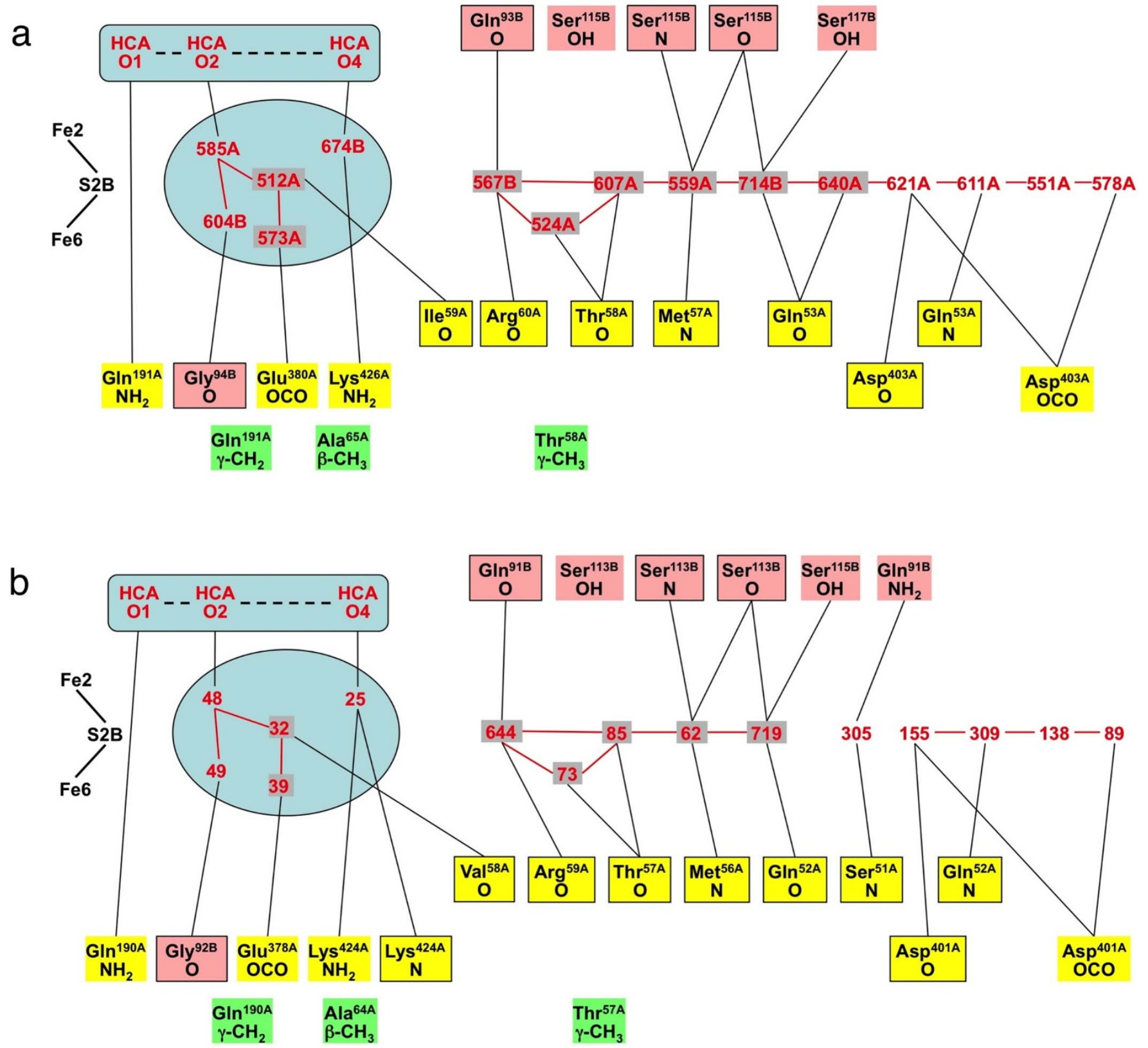

Figure 5 Schematic representations of the atoms involved in the postulated ammonia efflux channel in (a) $A v$ protein structure $3 \mathrm{U} 7 \mathrm{Q}$ and (b) Kp protein structure 1QH1. The numbering of O1/O2 and O3/O4 of HCA is reversed in PDB 1QH1, and has been changed to the 3U7Q numbering in this presentation. Water molecules are labeled red; protein atoms are differentiated as chain A yellow and chain B salmon, with main chain atoms boxed and side-chain atoms unboxed; connecting lines are possible hydrogen bonds. The groups coloured green are hydrophobic side-chain components that are potential steric barriers. The aqua enclosures signify the relevant components of the water pool.

molecules are $\mathrm{NH}_{3}\left(\right.$ or $\mathrm{NH}_{4}{ }^{+}$) because the crystallisation medium for structure 3U7Q did not contain $\mathrm{NH}_{3} / \mathrm{NH}_{4}{ }^{+}$buffers ${ }^{60}$.] Alternatively, is there space for $\mathrm{NH}_{3}$ to move around the water molecules in the resting protein? Would it be necessary for water molecules to move aside in order to allow passage of $\mathrm{NH}_{3}$ ?

The moving entity was modeled as $\mathrm{NH}_{3}$, because $\mathrm{NH}_{3}$ is generated at the surface of FeMo-co and is released into a hydrophobic anhydrous space. On diffusion into the water pool and beyond it is possible that $\mathrm{NH}_{4}{ }^{+}$is formed. In the early stages of the path there is no evident source of a replenishable proton, and so $\mathrm{NH}_{4}{ }^{+}$formation would be just a temporary relocation of one hydrogen atom across a hydrogen bond, and the following modeling of hydrogen bonds would be unchanged. Near the protein surface the more aqueous medium would generate $\mathrm{NH}_{4}{ }^{+}$.
Standard geometries were used for the three donor and one acceptor hydrogen bonds of $\mathrm{NH}_{3}$. The goal was to find a sequence of locations that engaged some or all of these possible hydrogen bonds, such that $\mathrm{NH}_{3}$ could swing from one location to the next, breaking and forming hydrogen bonds. The starting point had $\mathrm{NH}_{3}$ just dissociated from Fe6 $\left(\mathrm{Fe} 6-\mathrm{NH}_{3}=2.7 \AA\right)$, and $\mathrm{NH}_{3}$ hydrogen bonded to both $\mathrm{S} 2 \mathrm{~B}$ and $\mathrm{O} 1$ of HCA. It soon became evident that $\mathrm{NH}_{3}$ can only move away underneath the side chain of $\mathrm{Gln}^{191 \mathrm{~A}}$ into the water pool. Through this first stage of $\mathrm{NH}_{3}$ movement the important surroundings are $\mathrm{O} 1, \mathrm{O} 2$ and $\mathrm{O} 4$ of $\mathrm{HCA}$, the side-chain $\mathrm{CH}_{3}$ of $\mathrm{Ala}^{65 \mathrm{~A}}$, and both the terminal amide group and the $\mathrm{CH}_{2}$ functions of the side chain of $\mathrm{Gln}^{191 \mathrm{~A}}$. In the resting state the terminal $\mathrm{NH}_{2}$ of $\mathrm{Gln}^{191 \mathrm{~A}}$ is well positioned to donate hydrogen bonds to $\mathrm{O} 1 \mathrm{of}$ HCA and to the side chain carboxylate of $\mathrm{Glu}^{380 \mathrm{~A}}$. During this stage it 
is probable that the side chain amide group of $\operatorname{Gln}^{191 \mathrm{~A}}$ relocates and reconfigures in order the improve the hydrogen bonding with passing $\mathrm{NH}_{3}$, at the expense of the hydrogen bond to $\mathrm{O} 1$ and $\mathrm{OCO}$ of Glu $^{380 \mathrm{~A}}$.

Figure 6 shows the first six possible positions for $\mathrm{NH}_{3}$. Position 1 has $\mathrm{N}-\mathrm{H}$ hydrogen bonds to $\mathrm{S} 2 \mathrm{~B}$ and $\mathrm{O} 1$, then at position 2 the $\mathrm{N}-\mathrm{H}$ hydrogen bonds are bent to $\mathrm{O} 1$ and $\mathrm{O} 2$ of $\mathrm{HCA}$, then in position 3 breaking with $\mathrm{O} 1$ and in position 4 forming a new $\mathrm{N}-\mathrm{H}$ hydrogen bond to water $585 \mathrm{~A}$. In position 5 the $\mathrm{N}-\mathrm{H}$ hydrogen bond to water $585 \mathrm{~A}$ is retained and the other $\mathrm{N}-\mathrm{H}$ hydrogen bond bifurcates to $\mathrm{O} 1$ and $\mathrm{O} 2$, with a new hydrogen bond to water 512A. Finally, in position 6 the $\mathrm{NH}_{3}$ swings around its $\mathrm{N}-\mathrm{H}$ hydrogen bond to $\mathrm{O} 1$, and forms a new hydrogen bond to water 573A. Several comments are warranted. First, the $\mathrm{NH}_{3}$ trajectory is a downwardly spiraling arc maintained by $\mathrm{N}-\mathrm{H}$ hydrogen bonds to $\mathrm{O} 1$ and/or $\mathrm{O} 2$, and this carboxylate arm of HCA is regarded as a key controller of mechanism. Second, the side chain of $\mathrm{Gln}^{191 \mathrm{~A}}$ is closely involved, and with reconfiguration could form $\mathrm{Gln}^{191}-\mathrm{NH}_{2} \rightarrow \mathrm{NH}_{3}$ hydrogen bonds at positions 3, 5 and 6: these potential hydrogen bonds are marked on Fig. 6. Third, water molecules are used as hydrogen bond acceptors at positions 4,5 and 6 , with water molecules $512 \mathrm{~A}$ and $573 \mathrm{~A}$ moving by ca $0.7 \AA$ away from the approaching $\mathrm{NH}_{3}$ molecule. Sidechain $\beta-\mathrm{CH}_{3}$ of $\mathrm{Ala}^{65 \mathrm{~A}}$ and $\gamma-\mathrm{CH}_{2}$ of $\mathrm{Gln}^{191 \mathrm{~A}}$ provide steric boundaries.

This modeling was continued, stepping the hydrogen bonds of $\mathrm{NH}_{3}$, to identify a total of 18 possible locations for $\mathrm{NH}_{3}$ towards the protein surface. These positions are shown in Fig. 7 , together with the water molecules and significant amino-acid functions. Detail is provided in Supplementary Figs. S2 and S3. In the journey from the water pool to the cyan cavity $\mathrm{NH}_{3}$ passes between the sidechain of Lys ${ }^{426 \mathrm{~A}}$ and the main-chain oxygen atom of Ile ${ }^{59 \mathrm{~A}}$. The terminal $\mathrm{NH}_{2}$ function of Lys ${ }^{426 \mathrm{~A}}$ is a hydrogen bond accepting pivot point, and because the distances from it are slightly short it is proposed that this side-chain function moves slightly away during $\mathrm{NH}_{3}$ passage. The main-chain oxygen atoms of neighbouring residues $\mathrm{Thr}^{58 \mathrm{~A}}$, $\mathrm{Ile}^{59 \mathrm{~A}}$ and $\mathrm{Arg}^{60 \mathrm{~A}}$ function as hydrogen bond acceptors in positions 8 through 12 . The side chain $\mathrm{CH}_{3}$ function of $\mathrm{Thr}^{58 \mathrm{~A}}$ is significant, because the lone pairs of $\mathrm{NH}_{3}$ in positions 12 through 15 are distant $2.6-2.9 \AA$ from it, with the potential for formation of weak $\mathrm{C}-\mathrm{H} \rightarrow \mathrm{NH}_{3}$ hydrogen bonds. On the other side of this arced sequence of $\mathrm{NH}_{3}$ positions the side chains of $\mathrm{Ser}^{115}$ and $\mathrm{Ser}^{117}$ in chain

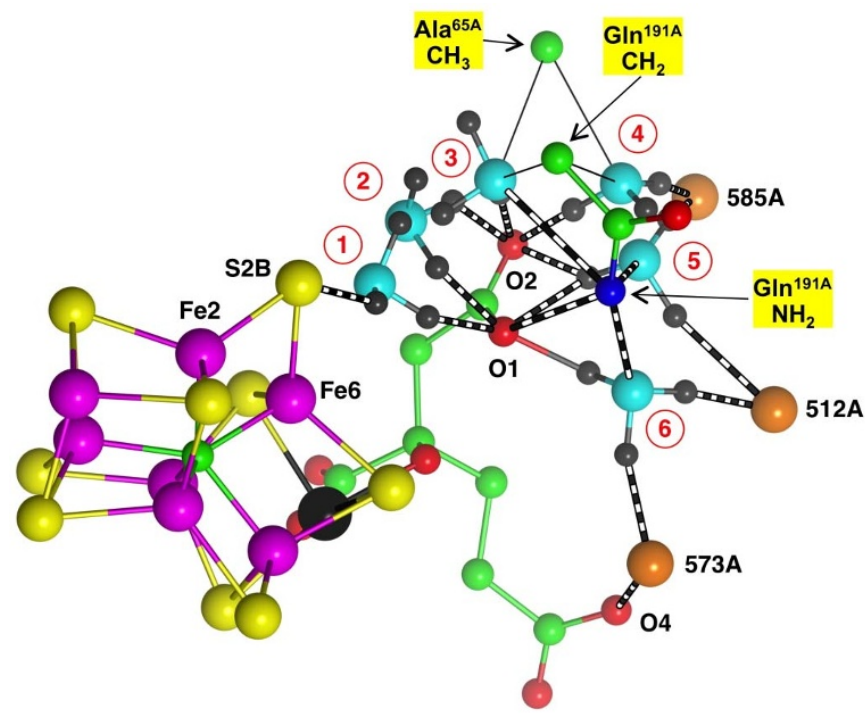

Figure 6 | The first six sequential positions (numbered 1-6) constructed for $\mathrm{NH}_{3}$. This representation is simplified in order to maintain the clarity of the multiple positions for $\mathrm{NH}_{3}$ ( $\mathrm{N}$ cyan, $\mathrm{H}$ gray) and its hydrogen bonds (black and white). The thin lines to $\beta-\mathrm{CH}_{3}$ of $\mathrm{Ala}^{65 \mathrm{~A}}$ and $\gamma-\mathrm{CH}_{2}$ of $\mathrm{Gln}^{191 \mathrm{~A}}$ signify steric boundaries for $\mathrm{NH}_{3}$ at positions 3 and 4 .
$\mathrm{B}$ are involved. Beyond the last modeled position, near $\mathrm{Gln}^{53 \mathrm{~A}}$, there is a 'river-delta' of possibilities for $\mathrm{NH}_{3}$ to escape to the protein surface. Examination of the atom thermal parameters for 3U7Q and 1GQU reveals that above average values occur in the sections of chains $A$ and $\mathrm{B}$ extending from the end of the $\mathrm{NH}_{3}$ pathway to the protein surface.

In positions through the cyan cavity domain, $\mathrm{N}-\mathrm{H} \rightarrow \mathrm{OH}_{2}$ hydrogen bonds are part of the model. The ability of these water molecules to accept one such hydrogen bond at each position of $\mathrm{NH}_{3}$ is favourable in terms of hydrogen atom accounting, because each water can form two other donor $\mathrm{O}-\mathrm{H} \rightarrow \mathrm{O}$ hydrogen bonds, one to the next water in the chain, and one to protein main chain carbonyl oxygen. Displacements of water molecules by $0.4-1.0 \AA$ are involved in the model, and it is clear that some local geometric reorganisation would be required as $\mathrm{NH}_{3}$ passed along this pathway.

This leads to considerations of secondary and tertiary structure, and structural fluctuations during $\mathrm{NH}_{3}$ passage. Figure 7 portrays this structure of the protein, and reveals the lack of secondary structure on the viewer side of the proposed path. The path winds between the A and B chains (see also Fig. 5), with the B chain occurring as a structured backdrop and the A chain as a movable front curtain. Figure 8 is a different view of key structural elements in the surrounding protein. Three different sections of the A chain are involved. The part of chain A that lies over the reaction face and contains $\mathrm{Val}^{70 \mathrm{~A}}$ is $\alpha$-helical only as far as residue 62 , but then is largely unstructured along the ammonia path to residue 52 (green). The section containing influential residues His ${ }^{195 \mathrm{~A}}$ and Gln ${ }^{191 \mathrm{~A}}$ (grey) is $\alpha$-helical only near FeMo-co. Glu ${ }^{380 \mathrm{~A}}$ and $\mathrm{Lys}^{426 \mathrm{~A}}$, both near the ammonia path, are connected by a long loop (yellow). Chain B (red) is near the proposed ammonia path at residues 93 and 115-117. The chain from 93 to 108 is $\alpha$-helical, directed well away from the ammonia pathway, then loops back to serines 115 and 117.

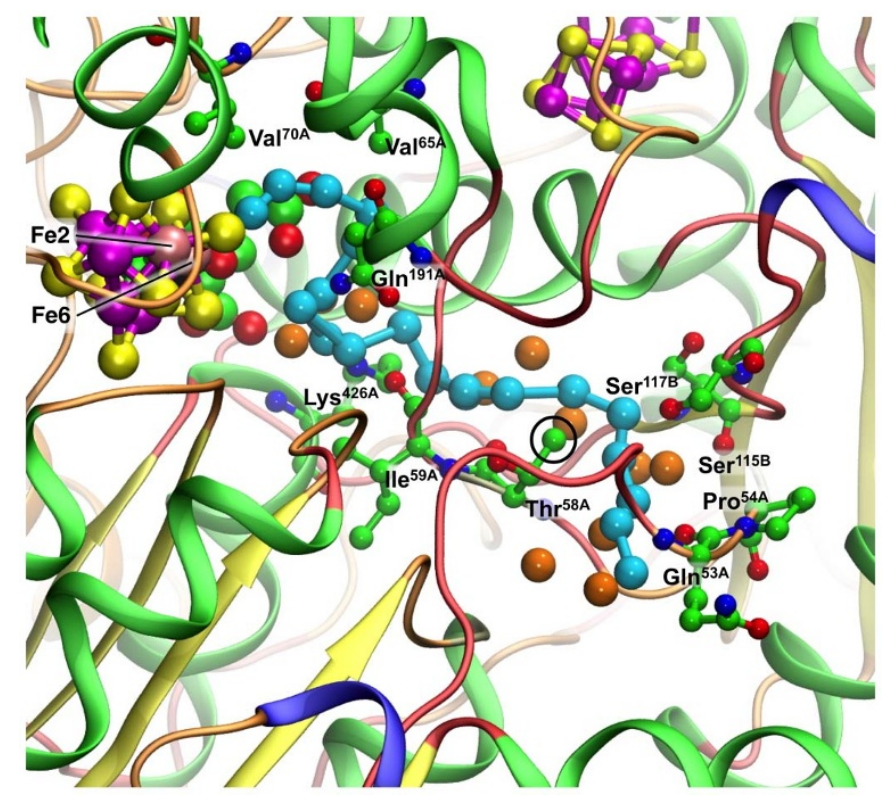

Figure $7 \mid$ The sequence of modeled positions for $\mathrm{NH}_{3}$ from the reaction face of FeMo-co towards the protein surface. Cyan spheres are the locations of the $\mathrm{N}$ atom: $\mathrm{H}$ atoms are not shown (but are included in Supplementary Figs. S2, S3). Orange spheres are water. Key interacting amino acids are marked and labeled. The side chain $\mathrm{CH}_{3}$ of $\mathrm{Thr}^{58 \mathrm{~A}}$ (circled) is significant, because the lone pairs of $\mathrm{NH}_{3}$ looping around it are 2.6-2.9 $\AA$ distant, with the potential for formation of weak $\mathrm{C}-\mathrm{H} \rightarrow$ $\mathrm{NH}_{3}$ hydrogen bonds. All protein chains are included and are coloured by structure ( $\alpha$-helix green, extended- $\beta$ yellow, turn orange, coil red), revealing the minimal secondary structure around most of the proposed $\mathrm{NH}_{3}$ pathway. 


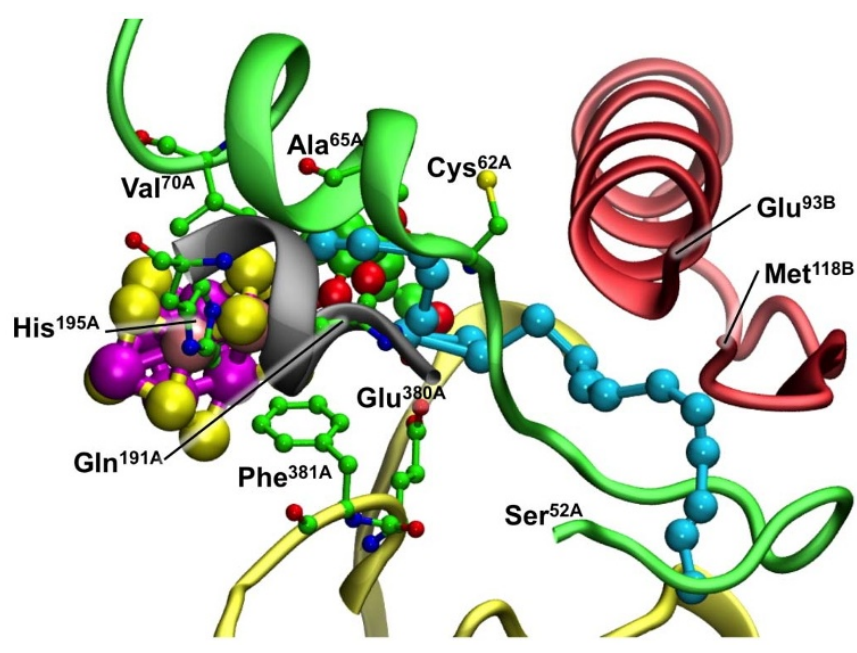

Figure $8 \mid$ The modeled $\mathrm{NH}_{3}$ pathway, emphasising secondary structure in the surrounding protein. Four different parts of chain A are involved. The A-chain helix over the reaction face (green) does not continue as chain A extends along the $\mathrm{NH}_{3}$ path from $\mathrm{Cys}^{62 \mathrm{~A}}$ to $\mathrm{Ser}^{52 \mathrm{~A}}$. The $\alpha$-helix of chain $\mathrm{B}$ (red) is near the $\mathrm{NH}_{3}$ pathway only at $\mathrm{Glu}^{93}$, then chain B loops back to flank the $\mathrm{NH}_{3}$ pathway near $\mathrm{Met}^{118}$.

The flexibility of these elements of the surroundings of the proposed ammonia pathway has been assessed via the crystallographic temperature factors. For crystal structure 1QGU (residue numbering as in Fig 5 (b)), the $C \alpha$ atoms of the helical section of chain A over the reaction face $\left(\mathrm{Val}^{69}\right.$ to $\mathrm{Cys}^{61}$ in 1QGU) have temperature factors well below average, but as the chain continues from residue 58 to lower numbered residues the $\mathrm{C} \alpha$ atom temperature factors increase to well above average, indicative of flexibility as the ammonia efflux extends towards the protein surface. In the B chain the below average temperature factors of the $\alpha$-helix (Fig. 8) increase through the key serine residues $(113,115)$ that are involved in the proposed ammonia pathway.

\section{Discussion}

This exploration of the structures of nitrogenase proteins has uncovered a pathway for the movement of product $\mathrm{NH}_{3}$ from its site of formation on FeMo-co to the surface of the protein, and a molecular mechanism for the translocation of $\mathrm{NH}_{3}$ has been developed. This pathway is conserved in proteins from species $A v, K p$ and $C p$. The integrity of the acid-base dimension of the physiological reaction of nitrogenase, consuming acid and generating base, is maintained, because the $\mathrm{NH}_{3}$ egress pathway is separate from and physically opposite to the proposed proton influx pathway. As in the glutamine amidotransferase enzymes, the moving entity in the early stages of the efflux is probably $\mathrm{NH}_{3}$, becoming $\mathrm{NH}_{4}{ }^{+}$near the protein surface.

Water molecules occur along most of the $\mathrm{NH}_{3}$ pathway, at least in the resting protein as crystallised, and provide acceptor and donor hydrogen bonding sites for $\mathrm{NH}_{3}$. Polypeptide main chain atoms also provide hydrogen bonding sites, and the suggested mechanism is essentially a sequence of interchanges of hydrogen bonds over short distances. The mechanism does not involve a flow of water molecules accompanying $\mathrm{NH}_{3}$, but it does involve movements of some water molecules away from the main path by distances of up to $1 \AA$, to create sufficient space for $\mathrm{NH}_{3}$ to skip from one hydrogen bond to the next.

At this point it is appropriate to make comparisons with the wellstudied ammonia channels in glutamine amidotransferase (GAT) enzymes. In all of these, ammonia generated by hydrolysis of glutamine (or asparagine) in the amidase domain is translocated through tunnels to a distant synthase site: the ammonia is shielded from the medium and maintained as $\mathrm{NH}_{3}$ because $\mathrm{NH}_{3}$ is needed as nucleophile in the synthase domain. The GAT enzymes are diverse in product, function and structure, and include carbamoyl phosphate synthetase ${ }^{68}$, glutamine phosphoribosylpyrophosphate amidotransferase (GPAT) $)^{46,69}$, glutamate synthase (GltS $)^{39}$, tRNA-dependent amidotransferases (or GatCAB). The ammonia tunnels are structured more by the residues of the synthase domain than those of the amidase domain, accounting for the variety of tunnel architectures ${ }^{39,40,70}$. In nitrogenase the formation of $\mathrm{NH}_{3}$ at FeMo-co is analogous to the formation of $\mathrm{NH}_{3}$ at the amidase site, but there is no requirement to prevent formation of $\mathrm{NH}_{4}{ }^{+}$near the end of the pathway at the surface of the MoFe protein. Nevertheless, there are results and interpretations from the amidotransferase enzymes that can inform further investigation and understanding of $\mathrm{NH}_{3}$ efflux from nitrogenase.

In crystalline GatCAB amidotransferases a $30-35 \AA$-long hydrophilic tunnel links the amidase and synthetase sites. The tunnel is ungated along its length, and contains 18 water molecules that are hydrogen bonded to each other or to surrounding polar residues. The published representations ${ }^{71,72}$ show a structure quite similar to that described here for nitrogenase. Molecular dynamics calculations have revealed gates and valves modulating the direction of $\mathrm{NH}_{3}$ transport ${ }^{47}$, and confirmed large barriers associated with $\mathrm{NH}_{4}{ }^{+}$ rather than $\mathrm{NH}_{3}$ as the moving entity. In glutamate synthase the tunnel is composed mainly of backbone atoms of hydrophilic residues, and water molecules fill the tunnel space ${ }^{39}$. There are some structural similarities between the various sections of the long intramolecular ammonia translocation tunnel in carbamoyl phosphate synthetase (CPS) ${ }^{68}$ and the path proposed here for nitrogenase. Molecular dynamics simulations of CPS reveal hydrogen bond stepping, movements of side-chains, and involvement of small water clusters. It is calculated that in the first stage of a long tunnel, $\mathrm{NH}_{3}$ is transported over a distance of $\sim 13 \AA$ with a maximum barrier of 6 $\mathrm{kcal} \mathrm{mol}^{-1} 44,45$. Further, it is suggested that water molecules have an important role in the transfer of $\mathrm{NH}_{3}$, because sites vacated by $\mathrm{NH}_{3}$ are refilled with water molecules such that the $\mathrm{NH}_{3}$ hydrogen bonds cannot reform, thereby forcing $\mathrm{NH}_{3}$ forward.

It is very probable that fluctuations of protein structure are part of the mechanism for nitrogenase, because the proposed route passes between different polypeptide chains, and those chain sections have minimal secondary structure and above average temperature factors. Gas transport channels in a variety of enzymes are characterised by structural flexibility ${ }^{73}$. Conformational variations are a primary feature of the ammonia-channeling glutamine amidotransferases ${ }^{41-43,46,47}$.

Amino acid Gln ${ }^{191 \mathrm{~A}}$ is a key component of the mechanism in nitrogenase, because it is normally hydrogen bonded through sidechain $\mathrm{NH}_{2}$ to $\mathrm{O} 1$ of HCA (another key component), and $\mathrm{NH}_{3}$ has to move around both of these atoms, and to avoid the side chain $\mathrm{CH}_{2}$ of Gln ${ }^{191 A}$, before escaping from the water pool (Fig. 6). Therefore the consequences of modification of this residue provide an experimental approach to testing the validity of the mechanism. Mutation of $\mathrm{Gln}^{191 \mathrm{~A}}$ to lysine with a longer side chain shuts down $\mathrm{NH}_{3}$ production from $\mathrm{N}_{2}{ }^{74}$, but $\mathrm{NH}_{3}$ is produced with azide as substrate by this mutant ${ }^{15}$, indicating that the $\mathrm{NH}_{3}$ efflux channel is not closed by Lys ${ }^{191 \mathrm{~A}}$. The interpretation of the diminished activity of the Lys ${ }^{191 \mathrm{~A}}$ mutant, that is only high $\mathrm{K}_{\mathrm{m}}$ reduction of $\mathrm{C}_{2} \mathrm{H}_{2}$ and no reduction of $\mathrm{N}_{2}$, is probably that given previously ${ }^{25}$, which is that Lys blocks hydrogenation steps at Fe6 but not hydrogenation steps at Fe2. I am not aware of other experimental data that bears on the validity of the $\mathrm{NH}_{3}$ efflux mechanism proposed here.

In this paper I have presented a plausible mechanistic pathway for egress of $\mathrm{NH}_{3}$ produced by nitrogenase. How can this proposal be tested? A standard experimental approach is modification of key amino acids and assessment of reactivity. The early stages of the $\mathrm{NH}_{3}$ path involve the side-chain of $\mathrm{Gln}^{191 \mathrm{~A}}$, in two ways: the terminal amide $\mathrm{NH}_{2}$ group engages some hydrogen bonds, while $\gamma-\mathrm{CH}_{2}$ provides a steric barrier. In view of the flexibility of the side-chain it is not surprising that lysine in this position does not fully shut down the 
escape of $\mathrm{NH}_{3}$, but large non-hydrogen bonding side-chains such as Phe or Trp at position 191A are predicted to impede the $\mathrm{NH}_{3}$ pathway. A large increase in size of the side-chain of residue $65 \mathrm{~A}$ could also interfere. Another significant side-chain is that of $\mathrm{Thr}^{58 \mathrm{~A}}$ (Fig. 7), because the proposed pathway passes closely around its $\gamma-\mathrm{CH}_{3}$. A more voluminous side-chain, without hydrogen bonding capability, could interfere with $\mathrm{NH}_{3}$ passage. These are suggestions for mutations to clog the pathway, but the likely fluctuations in protein structure may open alternative paths. In this context, residue 191A in the tighter earlier part of the $\mathrm{NH}_{3}$ route would be the prime target.

Might it be possible to incorporate a reagent for $\mathrm{NH}_{3}$ into the protein near the putative pathway, and then crystallise the protein containing the captured escaping $\mathrm{NH}_{3}$ ?

Computationally, a normal modes analysis ${ }^{75,76}$ of the protein structure would be informative about its flexibility around the proposed pathway. Molecular dynamics simulations, enhanced with various techniques ${ }^{44,46,77}$, should provide further insight into ammonia transport in nitrogenase.

\section{Methods}

The initial search for cavities was undertaken with the program fpocket ${ }^{61}$, using a procedure which strips water and heteroatoms (but not FeMo-co, homocitrate, or the P-cluster) from the atom coordinates ( $\mathrm{pdb}$ ) file, and then searches for alpha spheres. An alpha sphere contacts four atoms on its boundary and contains no internal atom: the four atoms are equally distant from the sphere centre, defining the radius of the sphere. Pockets are clusters of intersecting spheres, and pocket searches are controlled by filtering sphere properties such as radius, separation, and chemical attributes of the defining atoms. The variables in fpocket were first evaluated: for the searches of nitrogenase FeMo proteins, minimum alpha sphere radii in the range $2.7-3.0 \AA$ were found to be most informative, with pockets required to contain at least 35 alpha spheres. After each search the water excluded from the fpocket calculation was added back into the output files, in order to examine the presence of water in or near the pockets. Calculations of pockets were made for all of the high-resolution crystal structures (PDB 3U7Q, 1M1N, 2MIN, 3MIN, 2AFH, 2AFI, 1MIO, 1QGU, 1QH1, $1 \mathrm{QH} 8,1 \mathrm{H} 1 \mathrm{~L})$ that included the MoFe protein and a high proportion of resolved water molecules (the best structures contain ca 1300 water molecules per FeMo-co in the MoFe protein: structures 3K1A, 1M34 and 2AFK describe considerably less water).

A 3 U7Q pdb file with the modeled $\mathrm{NH}_{3}$ positions included is available from the author.

1. Burgess, B. K. \& Lowe, D. J. Mechanism of molybdenum nitrogenase. Chem. Rev. 96, 2983-3011 (1996).

2. Howard, J. B. \& Rees, D. C. Structural basis of biological nitrogen fixation. Chem. Rev. 96, 2965-2982 (1996).

3. Smith, B. E. Structure, function, and biosynthesis of the metallosulfur clusters in nitrogenases. Adv. Inorg. Chem. 47, 159-218 (1999).

4. Rees, D. C. \& Howard, J. B. Nitrogenase: standing at the crossroad. Curr. Opin. Chem. Biol. 4, 559-566 (2000).

5. Christiansen, J., Dean, D. R. \& Seefeldt, L. C. Mechanistic features of the Mocontaining nitrogenase. Annu. Rev. Plant Physiol. Plant Mol. Biol. 52, 269-295 (2001).

6. Igarashi, R. Y. \& Seefeldt, L. C. Nitrogen fixation: the mechanism of the Modependent nitrogenase. Crit. Rev. Biochem. Mol. Biol. 38, 351-384 (2003).

7. Rees, D. C. et al. Structural basis of biological nitrogen fixation. Phil. Trans. Roy. Soc. A 363, 971-984 (2005).

8. Seefeldt, L. C., Hoffman, B. M. \& Dean, D. R. Mechanism of Mo-Dependent Nitrogenase. Annu. Rev. Biochem. 78, 701-722 (2009).

9. Yang, Z.-Y., Danyal, K. \& Seefeldt, L. C. Mechanism of Mo-Dependent Nitrogenase. Methods Mol. Biol. 766, 9-29 (2011).

10. Seefeldt, L. C., Dance, I. G. \& Dean, D. R. Substrate Interactions with Nitrogenase: Fe versus Mo. Biochemistry 43, 1401-1409 (2004).

11. Dos Santos, P. C. et al. Substrate Interactions with the Nitrogenase Active Site. Acc. Chem. Res. 38, 208-214 (2005).

12. Sarma, R. et al. Insights into substrate binding at FeMo-cofactor in nitrogenase from the structure of an $\alpha-70^{\text {Ile }} \mathrm{MoFe}$ protein variant. J. Inorg. Biochem. 104, 385-389 (2010).

13. Dilworth, M. J., Fisher, K., Kim, C. H. \& Newton, W. E. Effects on substrate reduction of substitution of histidine-195 by glutamine in the alpha-subunit of the MoFe protein of Azotobacter vinelandii nitrogenase. Biochemistry 37, 17495-17505 (1998).

14. Fisher, K., Dilworth, M. J., Kim, C.-H. \& Newton, W. E. Azotobacter Vinelandii Nitrogenases Containing Altered MoFe Proteins with Substitutions in the FeMoCofactor Environment: Effects on the Catalyzed Reduction of Acetylene and Ethylene. Biochemistry 39, 2970-2979 (2000)

15. Fisher, K., Dilworth, M. J. \& Newton, W. E. Differential Effects on $\mathrm{N}_{2}$ Binding and Reduction, HD Formation, and Azide Reduction with $\alpha-195^{\text {His }}$ and $\alpha-191^{\text {Gln }}$
Substituted MoFe Proteins of Azotobacter Vinelandii Nitrogenase. Biochemistry 39, 15570-15577 (2000).

16. Christiansen, J., Cash, V. L., Seefeldt, L. C. \& Dean, D. R. Isolation and characterisation of an acetylene-resistant nitrogenase. J. Biol. Chem. 275, 11459-11464 (2000).

17. Christiansen, J., Seefeldt, L. C. \& Dean, D. R. Competitive Substrate and Inhibitor Interactions at the Physiologically Relevant Active Site of Nitrogenase. J. Biol. Chem. 275, 36104-36107 (2000).

18. Benton, P. M. C., Christiansen, J., Dean, D. R. \& Seefeldt, L. C. Stereospecificity of Acetylene Reduction Catalyzed by Nitrogenase. J. Am. Chem. Soc. 123, 1822-1827 (2001).

19. Benton, P. M. C. et al. Interaction of Acetylene and Cyanide with the Resting State of Nitrogenase $\alpha$-96-Substituted MoFe Proteins. Biochemistry 40, 13816-13825 (2001).

20. Barney, B. M. et al. Trapping a Hydrazine Reduction Intermediate on the Nitrogenase Active Site. Biochemistry 44, 8030-8037 (2005).

21. Barney, B. M. et al. Breaking the $\mathrm{N}_{2}$ triple bond: insights into the nitrogenase mechanism. Dalton Trans. 2277-2284 (2006).

22. Fisher, K. et al. Conformations generated during turnover of the Azotobacter vinelandii nitrogenase $\mathrm{MoFe}$ protein and their relationship to physiological function. J. Inorg. Biochem. 101, 1649-1656 (2007).

23. Dance, I. The Hydrogen Chemistry of the FeMo-co Active Site of Nitrogenase. J. Am. Chem. Soc. 127, 10925-10942 (2005).

24. Dance, I. The Correlation of Redox Potential, HOMO Energy, and Oxidation State in Metal Sulfide Clusters and Its Application to Determine the Redox Level of the FeMo-co Active-Site Cluster of Nitrogenase. Inorg. Chem. 45, 5084-5091 (2006).

25. Dance, I. Mechanistic Significance of the Preparatory Migration of Hydrogen Atoms around the FeMo-co Active Site of Nitrogenase. Biochemistry 45, 6328-6340 (2006).

26. Dance, I. The mechanistically significant coordination chemistry of dinitrogen at FeMo-co, the catalytic site of nitrogenase. J. Am. Chem. Soc. 129, 1076-1088 (2007).

27. Dance, I. Elucidating the Coordination Chemistry and Mechanism of Biological Nitrogen Fixation. Chem. Asian J. 2, 936-946 (2007).

28. Dance, I. The chemical mechanism of nitrogenase: calculated details of the intramolecular mechanism for hydrogenation of $\eta^{2}-\mathrm{N}_{2}$ on FeMo-co to $\mathrm{NH}_{3}$. Dalton Trans., 5977-5991 (2008).

29. Dance, I. The chemical mechanism of nitrogenase: hydrogen tunneling and further aspects of the intramolecular mechanism for hydrogenation of $\eta^{2}-\mathrm{N}_{2}$ on FeMo-co to $\mathrm{NH}_{3}$. Dalton Trans., 5992-5998 (2008).

30. Dance, I. Nitrogenase: a general hydrogenator of small molecules. Chem. Commun. 49, 10893-10907 DOI:10.1039/C3CC46864J (2013).

31. Dance, I. The controlled relay of multiple protons required at the active site of nitrogenase. Dalton Trans. 41, 7647-7659 (2012).

32. Durrant, M. C. Controlled protonation of iron-molybdenum cofactor by nitrogenase: a structural and theoretical analysis. Biochem. J. 355, 569-576 (2001).

33. Khademi, S. et al. Mechanism of Ammonia Transport by Amt/MEP/Rh: Structure of AmtB at $1.35 \AA$ A. Science 305, 1587-1594 (2004).

34. Andrade, S. L. A., Dickmanns, A., Ficner, R. \& Einsle, O. Crystal structure of the archaeal ammonium transporter Amt-1 from Archaeoglobus fulgidus. Proc. Natl. Acad. Sci. U.S.A. 102, 14994-14999 (2005).

35. Andrade, S. L. A. \& Einsle, O. The Amt/Mep/Rh family of ammonium transport proteins (Review). Mol. Membr. Biol. 24, 357-365 (2007).

36. Javelle, A. et al. Structural and mechanistic aspects of Amt/Rh proteins. J. Struct. Biol. 158, 472-481 (2007).

37. Thoden, J. B., Holden, H. M., Wesenberg, G., Raushel, F. M. \& Rayment, I. Structure of Carbamoyl Phosphate Synthetase: A Journey of $96 \AA$ from Substrate to Product. Biochemistry 36, 6305-6316 (1997).

38. Raushel, F. M., Thoden, J. B. \& Holden, H. M. Enzymes with Molecular Tunnels Acc. Chem. Res. 36, 539-548 (2003).

39. van den Heuvel, R. H., Curti, B., Vanoni, M. A. \& Mattevi, A. Glutamate synthase: a fascinating pathway from L-glutamine to L-glutamate. Cell. Mol. Life Sci. 61, 669-681 (2004).

40. Weeks, A., Lund, L. \& Raushel, F. M. Tunneling of intermediates in enzymecatalyzed reactions. Curr. Opin. Chem. Biol. 10, 465-472 (2006).

41. Mouilleron, S. \& Golinelli-Pimpaneau, B. Conformational changes in ammoniachanneling glutamine amidotransferases. Curr. Opin. Struct. Biol. 17, 653-664 (2007).

42. Mouilleron, S., Badet-Denisot, M.-A., Badet, B. \& Golinelli-Pimpaneau, B. Dynamics of glucosamine-6-phosphate synthase catalysis. Arch. Biochem. Biophys. 505, 1-12 (2011).

43. Mouilleron, S., Badet-Denisot, M.-A. \& Golinelli-Pimpaneau, B. Ordering of Cterminal Loop and Glutaminase Domains of Glucosamine-6-Phosphate Synthase Promotes Sugar Ring Opening and Formation of the Ammonia Channel. J. Mol. Biol. 377, 1174-1185 (2008).

44. Fan, Y., Lund, L., Yang, L., Raushel, F. M. \& Gao, Y.-Q. Mechanism for the Transport of Ammonia within Carbamoyl Phosphate Synthetase Determined by Molecular Dynamics Simulations. Biochemistry 47, 2935-2944 (2008).

45. Fan, Y., Lund, L., Shao, Q., Gao, Y.-Q. \& Raushel, F. M. A Combined Theoretical and Experimental Study of the Ammonia Tunnel in Carbamoyl Phosphate Synthetase. J. Am. Chem. Soc. 131, 10211-10219 (2009). 
46. Wang, X. S., Roitberg, A. E. \& Richards, N. G. J. Computational Studies of Ammonia Channel Function in Glutamine 5'-Phosphoribosylpyrophosphate Amidotransferase. Biochemistry 48, 12272-12282 (2009).

47. Kang, J., Kuroyanagi, S., Akisada, T., Hagiwara, Y. \& Tateno, M. Unidirectional Mechanistic Valved Mechanisms for Ammonia Transport in GatCAB. J. Chem. Theory Computation 8, 649-660 (2012).

48. Marini, A.-M., Urrestarazu, A., Beauwens, R. \& André, B. The Rh (Rhesus) blood group polypeptides are related to $\mathrm{NH}_{4}{ }^{+}$transporters. Trends Biochem. Sci. 22, 460-461 (1997).

49. Gruswitz, F. et al. Function of human Rh based on structure of RhCG at $2.1 \AA$. Proc. Nat. Acad. Sci. USA 107, 9638-9643 (2010).

50. Zheng, L., Kostrewa, D., Bernèche, S., Winkler, F. K. \& Li, X.-D. The mechanism of ammonia transport based on the crystal structure of AmtB of Escherichia coli. Proc. Natl. Acad. Sci. U.S.A. 101, 17090-17095 (2004).

51. Nygaard, T. P., Rovira, C., Peters, G. H. \& Jensen, M. Ø. Ammonium Recruitment and Ammonia Transport by E. coli Ammonia Channel AmtB. Biophys. J. 91, 4401-4412 (2006).

52. Bostick, D. L. \& Brooks, C. L. Deprotonation by Dehydration: The Origin of Ammonium Sensing in the AmtB Channel. PLoS Comput. Biol. 3, e22 (2007).

53. Gruswitz, F., O'Connell, J. \& Stroud, R. M. Inhibitory complex of the transmembrane ammonia channel, $\mathrm{AmtB}$, and the cytosolic regulatory protein, GlnK, at $1.96 \AA$ A. Proc. Nat. Acad. Sci. USA 104, 42-47 (2007).

54. Ishikita, H. \& Knapp, E.-W. Protonation States of Ammonia/Ammonium in the Hydrophobic Pore of Ammonia Transporter Protein AmtB. J. Am. Chem. Soc. 129, 1210-1215 (2007).

55. Javelle, A. et al. Substrate binding, deprotonation, and selectivity at the periplasmic entrance of the Escherichia coli ammonia channel AmtB. Proc. Nat. Acad. Sci. USA 105, 5040-5045 (2008).

56. Hall, J. A. \& Kustu, S. The pivotal twin histidines and aromatic triad of the Escherichia coli ammonium channel AmtB can be replaced. Proc. Nat. Acad. Sci. USA 108, 13270-13274 (2011).

57. Wang, S., Orabi, E. A., Baday, S., Bernèche, S. \& Lamoureux, G. Ammonium Transporters Achieve Charge Transfer by Fragmenting Their Substrate. J. Am Chem. Soc. 134, 10419-10427 (2012).

58. Ullmann, R. T., Andrade, S. L. A. \& Ullmann, G. M. Thermodynamics of Transport Through the Ammonium Transporter Amt-1 Investigated with Free Energy Calculations. J. Phys. Chem. B 116, 9690-9703 (2012).

59. Hall, J. A. \& Yan, D. The Molecular Basis of $\mathrm{K}^{+}$Exclusion by the Escherichia coli Ammonium Channel AmtB. J. Biol. Chem. 288, 14080-14086 (2013).

60. Spatzal, T. et al. Evidence for Interstitial Carbon in Nitrogenase FeMo Cofactor. Science 334, 940 (2011).

61. Guilloux, V. L., Schmidtke, P. \& Tuffery, P. Fpocket: An open source platform for ligand pocket detection. BMC Bioinformatics 10, 168 (2009).

62. Einsle, O. et al. Nitrogenase MoFe-Protein at $1.16 \AA$ Resolution: A Central Ligand in the FeMo-Cofactor. Science 297, 1696-1700 (2002).

63. Peters, J. W. et al. Redox-Dependent Structural Changes in the Nitrogenase PCluster. Biochemistry 36, 1181-1187 (1997).

64. Tezcan, F. A. et al. Nitrogenase Complexes: Multiple Docking Sites for a Nucleotide Switch Protein. Science 309, 1377-1380 (2005)

65. Kim, J., Woo, D. \& Rees, D. C. X-ray Crystal Structure of the Nitrogenase Molybdenum-Iron Protein from Clostridium pasteurianum at $3.0 \AA$ Resolution. Biochemistry 32, 7104-7115 (1993).

66. Mayer, S. M., Lawson, D. M., Gormal, C. A., Roe, S. M. \& Smith, B. E. New insights into structure-function relationships in nitrogenase: a $1.6 \AA$ resolution $\mathrm{X}$-ray crystallographic study of Klebsiella pneumoniae MoFe protein. J. Mol. Biol. 292, 871-891 (1999)

67. Mayer, S. M., Gormal, C. A., Smith, B. E. \& Lawson, D. M. Crystallographic Analysis of the MoFe Protein of Nitrogenase from a nifV Mutant of Klebsiella pneumoniae Identifies Citrate as a Ligand to the Molybdenum of Iron Molybdenum Cofactor (FeMoco). J. Biol. Chem. 277, 35263-35268 (2002).

68. Thoden, J. B., Raushel, F. M., Benning, M. M., Rayment, I. \& Holden, H. M. The structure of carbamoyl phosphate synthetase determined to $2.1 \AA$ resolution. Acta Crystallogr. D Biol. Crystallogr. 55, 8-24 (1999).

69. Smith, J. L. Glutamine PRPP amidotransferase: snapshots of an enzyme in action. Curr. Opin. Struct. Biol. 8, 686-694 (1998).

70. Vanoni, M. A. \& Curti, B. Structure-function studies of glutamate synthases: A class of self-regulated iron-sulfur flavoenzymes essential for nitrogen assimilation. IUBMB Life 60, 287-300 (2008).

71. Nakamura, A., Yao, M., Chimnaronk, S., Sakai, N. \& Tanaka, I. Ammonia Channel Couples Glutaminase with Transamidase Reactions in GatCAB. Science 312, 1954-1958 (2006).

72. Wu, J. et al. Insights into tRNA-Dependent Amidotransferase Evolution and Catalysis from the Structure of the Aquifex aeolicus Enzyme. J. Mol. Biol. 391, 703-716 (2009).

73. Fontecilla-Camps, J. C., Amara, P., Cavazza, C., Nicolet, Y. \& Volbeda, A. Structure-function relationships of anaerobic gas-processing metalloenzymes. Nature 460, 814-822 (2009).

74. Scott, D. J., Dean, D. R. \& Newton, W. E. Nitrogenase-catalyzed Ethane Production and CO-sensitive Hydrogen Evolution from MoFe Proteins Having Amino Acid Substitutions in an a-Subunit FeMo Cofactor-binding Domain. J. Biol. Chem. 267, 20002-20010 (1992).

75. Berendsen, H. J. C. \& Hayward, S. Collective protein dynamics in relation to function. Curr. Opin. Struct. Biol. 10, 165-169 (2000).

76. Floquet, N. et al. Collective motions in Glucosamine-6-phosphate Synthase: Influence of Ligand Binding and role in Ammonia Channelling and Opening of the Fructose-6-Phosphate Binding Site. J. Mol. Biol. 385, 653-664 (2009).

77. Henzler-Wildman, K. \& Kern, D. Dynamic personalities of proteins. Nature 450, 964-972 (2007)

\section{Acknowledgments}

This research was supported by the University of New South Wales.

\section{Additional information}

Supplementary information accompanies this paper at http://www.nature.com/ scientificreports

Competing financial interests: The author declares no competing financial interests. How to cite this article: Dance, I. A molecular pathway for the egress of ammonia produced by nitrogenase. Sci. Rep. 3, 3237; DOI:10.1038/srep03237 (2013)

This work is licensed under a Creative Commons AttributionNonCommercial-NoDerivs 3.0 Unported license. To view a copy of this license, visit http://creativecommons.org/licenses/by-nc-nd/3.0 